\title{
Relevance of PD-LI Non-Coding Polymorphisms on the Prognosis of a Genetically Admixed NSCLC Cohort
}

This article was published in the following Dove Press journal: Pharmacogenomics and Personalized Medicine

\begin{abstract}
Juliana Machado-Rugolo, (iD 1,2
Tabatha Gutierrez Prieto, (D)

Alexandre Todorovic Fabro, (iD) ${ }^{3}$

Edwin Roger Parra Cuentas, ${ }^{4}$

Vanessa Karen Sá, (iD ${ }^{5}$

Camila Machado Baldavira, (iD)

Claudia Aparecida Rainho, (iD ${ }^{6}$

Erick C Castelli, (iD) ${ }^{7,8}$ Cecilia Farhat,'

Teresa Yae Takagaki, (iD) ${ }^{9}$

Maria Aparecida Nagai, (iD 10,1

Vera Luiza Capelozzi (iD)

'Laboratory of Genomics and Histomorphometry, Department of Pathology, University of São Paulo Medical School (USP), São Paulo, Brazil; ${ }^{2}$ Health Technology Assessment Center, Clinical Hospital (HCFMB), Medical School of São Paulo State University (UNESP), Botucatu, São Paulo, Brazil; ${ }^{3}$ Department of Pathology and Legal Medicine, Ribeirão Preto School of Medicine, University of São Paulo (FMRP-USP), Ribeirão Preto, Brazil;

${ }^{4}$ Department of Translational Molecular Pathology,

The University of Texas MD Anderson Cancer

Center, Houston, Texas, USA; ${ }^{5}$ Laboratory of

Genomics and Molecular Biology, Centro

Internacional De Pesquisa (CIPE), AC Camargo

Cancer Center, São Paulo, SP, Brazil; ${ }^{6}$ Department of

Chemical and Biological Sciences, Institute of

Biosciences, São Paulo State University (UNESP),

Botucatu, São Paulo, Brazil; ${ }^{7}$ Molecular Genetics and

Bioinformatics Laboratory, Experimental Research

Unit (UNIPEX), Medical School of São Paulo State

University (UNESP), Botucatu, São Paulo, Brazil;

${ }^{8}$ Department of Pathology, Medical School of São

Paulo State University (UNESP), Botucatu, São

Paulo, Brazil; 'Division of Pneumology, Heart

Institute (Incor), Clinical Hospital, University of São

Paulo Medical School (USP), São Paulo, São Paulo,

Brazil; ${ }^{10}$ Department of Radiology and Oncology,

University of São Paulo Medical School (USP), São

Paulo, Brazil; " 'Laboratory of Molecular Genetics,

Center for Translational Research in Oncology,

Cancer Institute of São Paulo (ICESP), São Paulo,

Brazil
\end{abstract}

Correspondence: Vera Luiza Capelozzi

Department of Pathology, University of São

Paulo Medical School (USP), Av Dr Arnaldo

455, Room I I43, São Paulo, São Paulo State,

0I246-903, Brazil

Tel +55 II 30617427

Fax +55 II 3064-2744

Email vera.capelozzi@fm.usp.br
Purpose: Although non-small cell lung cancer (NSCLC) remains a deadly disease, new predictive biomarkers have emerged to assist in managing the disease, of which one of the most promising is the programmed death-ligand 1 (PD-L1). Each, $P D-L 1$ variant seem to modulate the function of immune checkpoints differently and affect response to adjuvant treatment and outcome in NSCLC patients. We thus investigated the influence of these PDL1 genetic variations in genetically admixed NSCLC tissue samples, and correlated these values with clinicopathological characteristics, including prognosis.

Materials and Methods: We evaluated PD-L1 non-coding genetic variants and protein expression in lung adenocarcinomas (ADC), squamous cell carcinomas (SqCC), and large cell carcinomas (LCC) in silico. Microarray paraffin blocks from 70 samples of ADC $(\mathrm{N}=33)$, SqCC $(\mathrm{N}=24)$, and LCC $(\mathrm{N}=13)$ were used to create PD-L1 multiplex immunofluorescence assays with a Cell Signaling E1L3N clone. Fifteen polymorphisms of the $P D-L 1$ gene were investigated by targeted sequencing and evaluated in silico using dedicated tools.

Results: Although $P D-L 1$ polymorphisms seemed not to interfere with protein expression, PD-L1 expression varied among different histological subtypes, as did clinical outcomes, with the rs $4742098 \mathrm{~A}>\mathrm{G}, \mathrm{rs} 4143815 \mathrm{G}>\mathrm{C}$, and $\mathrm{rs} 7041009 \mathrm{G}>\mathrm{A}$ variants being associated with relapse $(P=0.01 ; P=0.05 ; P=0.02$, respectively). The rs 7041009 GG genotype showed a significant correlation with younger and alive patients compared to carriers of the A allele ( $P=0.02$ and $P<0.01$, respectively). The Cox regression model showed that the rs7041009 GG genotype may influence OS $(P<0.01)$ as a co-dependent factor associated with radiotherapy and recurrence in NSCLC patients. Furthermore, the Kaplan-Meier survival curves showed that rs7041009 and rs4742098 might impact PPS in relapsed patients. In silico approaches identified the variants as benign.

Conclusion: $P D-L 1$ non-coding variants play an important role in modulating immune checkpoint function and may be explored as immunotherapy biomarkers. We highlight the rs7041009 variant, which impacts OS and PPS in NSCLC patients.

Keywords: $P D-L 1$, non-small cell lung cancer, single nucleotide polymorphisms, nextgeneration sequencing

\section{Introduction}

Lung cancer is one of the leading causes of cancer-related death globally. ${ }^{1}$ Although there are different types of lung cancer, non-small cell lung cancer (NSCLC) represents $85 \%$ of all primary lung tumors. NSCLC is a grim disease that is aggravated by the fact that patients normally either receive their diagnosis at advanced stages or present with recurrent disease after initial locoregional 
treatment. $^{2}$ Over the last few decades, conventional chemotherapy, mainly platinum-based chemotherapy, used to be the only therapeutic option for those not eligible for radical intent treatment: a treatment with limited efficacy and very few long-term survivors (5-year overall survival less than 15\%). Furthermore, these patients often lacked therapeutic options beyond first-line treatment. ${ }^{3}$

More recently, though, immune checkpoint molecules involved in tumor immune evasion were identified and immune checkpoint inhibitors (ICIs) were introduced in antitumor immunotherapy. This new therapeutic approach targets an inhibitory receptor, the programmed cell death-1 (PD-1) receptor, to assist the immune system in identifying and neutralizing malignant cells. However, tumor cells may evade the host immunosurveillance by expressing the programmed death-1-ligand 1 (PD-L1) as an adaptive, resistant mechanism to suppress this inhibitory receptor. ${ }^{4}$ Thus, because PD-L1 up-regulation by tumor cells can protect them from antitumor immune response, the blockade of PD-L1/PD-1 interactions has been recently selected for antitumor immune therapy. ${ }^{5}$ Agents targeting the PD-1/ PD-L1 signaling pathway have shown promising responses in different types of cancer, including NSCLC. These results point to PD-L1 protein expression as a potential predictive marker for a successful blockade of PD-L1/PD-1 interactions. ${ }^{6}$ However, several challenges remain in producing robust evidence to support the use of this biomarker.

In this context, some studies with NSCLC patients have demonstrated that those with more than 50\% PD-L1 positive tumor cells are non-responders to anti-PD-1/PD-L1 treatment. In contrast, others have shown that patients whose tumors do not express PD-L1 are good responders. ${ }^{7-9}$ To explain the controversies that affect PD-L1 expression, some studies have considered that the heterogeneity between axis expression and response to PD-1/PD-L1 treatment in NSCLC depends on other factors, such as more precise methods to investigate immune evasion mechanisms and the immune microenvironment, as well as greater knowledge on the immune checkpoint genomic profile and the genetic variants of the $P D-L 1$ gene. ${ }^{10-13}$

Some genetic variants have been shown to affect normal gene activation and transcriptional initiation, and hence influence the amount of mRNA and encoded protein in the cell. ${ }^{14}$ Non-coding variants also presumably affect genetic regulatory elements, since a majority of driver variants in cancer genomes occur in non-coding regions. ${ }^{15,16}$
Thus, several studies have investigated the association between $P D-1$ and $P D-L 1$ genetic variants and the risk of various cancers, but their findings have yet failed to completely elucidate this question. ${ }^{17}$ A previous study suggested that $P D-L 1$ polymorphism may predict chemotherapy response and survival rates in advanced-stage NSCLC patients after first-line paclitaxel-cisplatin. ${ }^{18}$ More recently, $P D-L 1$ copy number variations, point mutations, and 3'-UTR disruptions have been highlighted as genetic mechanisms of PDL1 deregulation. ${ }^{19}$ Furthermore, previous research on Brazilian patients suggested that their ethnic background could account for their distinct cancer's molecular profile, perhaps due to their characteristic genetic admixture, inherited from European, African, and Native American ancestors. ${ }^{20-22}$

We hypothesize that $P D-L 1$ non-coding genetic variants modulate the function of this immune checkpoint in NSCLC. To explore this issue, we investigated fifteen $P D-L 1$ non-coding genetic variants using nextgeneration sequencing (NGS) in a Brazilian cohort, aiming to uncover the effect of their ethnic admixture on NSCLC. We also combined our analyses with an insilico approach to predict the impact of these genetic variants on the disease. We evaluated the associations between PD-L1 protein expression level and clinicopathological characteristics, including the prognosis of NSCLC patients undergoing surgical resection, glimpsing the impact of genetic variants on post progression survival (PPS) and overall survival (OS). Herein, in this context, we intend to expand the existing literature on $P D-L 1$ gene alterations at the genetic level and their impact on NSCLC in patients from different ethnicities, thus increasing the knowledge about the molecular basis of immunotherapy biomarkers.

\section{Materials and Methods Cohort}

In this retrospective multi-center study, we obtained archival formalin-fixed paraffin-embedded histologic tumor sections from 70 patients diagnosed with NSCLC (33 adenocarcinomas [ADC], 24 squamous cell carcinoma $[\mathrm{SqCC}]$ and 13 large cell carcinoma [LCC]) who underwent surgical resection between January 1, 1995, and December 31, 2015. Patients had been treated at the Hospital das Clínicas of the University of São Paulo Medical School (HC-FMUSP), 
at the Heart Institute of the University of São Paulo (INCOR), at the Cancer Institute of São Paulo (ICESP), and at the A.C. Camargo Cancer Center in São Paulo, Brazil.

All samples were histologically reviewed by lung pathologists who selected samples with at least $30 \%$ of lung cancer cells before nucleic acid extraction. The samples were classified using the 2017 International Association for the Study of Lung Cancer (IASLC) classification system. ${ }^{23}$ The clinicopathological features of patients were obtained from the medical records. The study was approved in accordance with the ethical standards of the responsible committee on human experimentation local (Research Ethics Committee of University of São Paulo Medical School - CAAE: 79769017.1.0000.5440; opinion number: 2.673.320) and with the 1964 Helsinki declaration. A waiver of the requirement for informed consent was obtained from committee, and to identity of the subjects under this retrospective analysis was omitted and anonymized.

\section{Multiplex Immunofluorescence Staining}

We performed a Multiplex immunofluorescence (mIF) staining using methods that had been previously described and validated. ${ }^{24,25}$ Four-micrometer-thick consecutive TMA sections were stained using an automated staining system (BOND-RX; Leica Biosystems, Buffalo Grove, IL) to characterize PD-L1 (clone E1L3N, dilution 1:100; Cell Signaling Technology, Danvers, MA). The PD-L1 marker was stained with its respective fluorophore from the Opal 7 kit (catalogue \#NEL797001KT; Akoya Biosciences/ PerkinElmer, Waltham, MA). A complete validation using immunofluorescence (IF) allowed us to obtain a uniform, specific, and appropriate signal across all the channel; ie, a well-balanced staining pattern for the multiplex staining. ${ }^{24,25}$ We also defined and optimized the correct fluorophore signals between 10 and 30 counts of intensity to maintain good balance and similar thresholds of intensity across all antibodies. In parallel, to detect possible variations in staining and optimize the separation of the signal, positive and negative (autofluorescence) controls were included during the staining process to ensure that all the antibodies performed well together. Autofluorescence controls with an expected spectral resolution of $488 \mathrm{~nm}$ were able to accurately remove the autofluorescence from all the label signals during the analysis. The stained slides were then scanned using a multispectral microscope, the Vectra Polaris 3.0 imaging system (Akoya
Biosciences/PerkinElmer, Waltham, MA), under fluorescence conditions.

\section{Multiplex Immunofluorescence Quantitation}

Multispectral images of tumor sections from each core were analyzed with inForm 2.2.1 (Akoya Biosciences/ PerkinElmer, Waltham, MA) software Individual cells, which were defined by nuclei staining and identified by the InForm cell segmentation tool, were subjected to a phenotyping pattern-recognition learning algorithm to characterize co-localization of the various cell populations using panel labeling. ${ }^{26}$ The panel labeling was as follows: Malignant cells (MCs), with the AE1/AE3+ marker, including those with and without PD-L1 expression (AE1/AE3+ PD-L1+ and AE1/AE3+ PD-L1-, respectively). The individual cell phenotype report produced by the InForm software was processed using Excel 2010 (Microsoft. Houston, TX), and a final summary of the data, which contained the median of each individual phenotype (given as number of cells $/ \mathrm{mm}^{2}$ ) and the percentage of macrophages and MCs expressing PD-L1, was created for statistical analysis. If the percentage of MCs or macrophages expressing PD-L1was greater than the median value, the PD-L1 expression was considered positive. If the percentage of macrophages or MCs expressing PD-L1 was lower than or equal to the median, the PD-L1 expression was considered negative.

\section{DNA Extraction}

Genomic DNA (gDNA) was extracted from frozen NSCLC tissue using the QIAamp DNA Mini Kit (Qiagen, Hilden, Germany) according to the manufacturer's recommendations. DNA concentration was measured using the Qubit ${ }^{\circledR}$ 3.0 Fluorometer (Invitrogen, Life Technologies, CA, USA). DNA integrity was assessed using the Bioanalyzer 2100 system (Agilent Technologies, CA, USA).

\section{Sequencing and Data Analysis}

We performed a $P D-L 1$ (CD274) full gene screening by deep targeted sequencing using the TruSeq Custom Amplicon Panel v1.5 kit (TSCAP, Illumina, SanDiego, CA) and the MiSeq platform (Illumina, SanDiego, CA). The DNA libraries were performed according to the manufacturer's instructions and consisted of $150 \mathrm{bp}$ paired-end reads (300 cycles). 
We performed an NGS data analysis on the Molecular Genetics and Bioinformatics Laboratory of the Experimental Research Unit (UNIPEX) at the Medical School of São Paulo State University (FMBUNESP). Sequencing quality was assessed by FastQC. Reads were aligned to the human genome (hg19, GRCh37) with BWA software, and SAM tools converted the alignment results to BAM format. ${ }^{27}$ Next, the mapped reads underwent variant calling for SNP with GATK command line tools, including HaplotypeCaller, SelectVariants, and VariantFiltration programs with default parameters. After the calling step, the variants were annotated using the $\mathrm{VEP}^{28}$ software. Coverage depth was a priori set at $100 \times$. Variants had to have $>10$ reads of position depth (PD) and/or $>6$ reads of allele depth (AD) and/or an $\mathrm{AD} / \mathrm{PD}$ ratio of $>0.05$ and/ or a population frequency higher than $1 \%$ (popfreq_all $>0.01$ ) were included in the study. Finally, variants were compared using ABraOM, a web-based public database of Brazilian genomic variants. ${ }^{29}$

\section{In silico Prediction of Non-Coding Genetic Variants}

Several tools were used to predict potential functional effects of SNPs on non-coding binding sites, such as splice sites and binding sites for transcription factors, exonic splicing enhancers (ESEs), and microRNA (miRNA). The impact of each genetic variant was assessed using VarSome $^{30}$ an integrated search engine that allows access to several databases, forecasting tools, and publications on a single website. Variant pathogenicity was reported using an automatic variant classifier that evaluates each submitted variant according to guideline of the American College of Medical Genetics and Genomics (ACMG) and classifies it as either "pathogenic", "likely pathogenic", "likely benign", "benign" or "uncertain significance". Varsome predicts the pathogenicity of each variant through a DANN ${ }^{31}$ score, a methodology for scoring deleterious annotations of genetic variants using neural networks that results in a number ranging from 0 to 1 . Higher DANN scores represent greater variant deleteriousness. ${ }^{31}$

Next, we applied the Genomic Evolutionary Rate Profiling (GERP) ${ }^{32,33}$ conservation score. This score is used to calculate the reduction of substitutions in a multispecies sequence alignment when compared to a neutral expectation. GERP scores $>5.5$ are strongly associated with a purifying selection. Mutations that occur at highly conserved sites in many species are assumed as harmful and therefore contribute to the genetic load within a species.

Finally, we used two tools, SNPinfo (FuncPred) ${ }^{34}$ and RegulomeDB, ${ }^{35}$ to track SNPs according to their functions. SNPinfo is a web server that helps researchers investigate SNPs in studies of genetic association and provide different pipelines for SNP selection, whereas RegulomeDB is an online composite database and prediction tool to annotate and prioritize potential regulatory variants from the human genome. ${ }^{35}$ RegulomeDB divides the variants into six categories: category 1 variants are likely to affect binding and are linked to the expression of a gene target, category 2 variants are likely to affect binding, category 3 variants are less likely to affect binding, and category 4,5 , and 6 variants have minimal binding evidence. ${ }^{35}$

\section{Statistical Analysis}

The allelic and genotypic frequencies of the $P D-L 1$ polymorphisms found in NSCLC were calculated by Hardy Weinberg equilibrium $([1 \ldots(\mathrm{hC} 2 \mathrm{H})] / 2 \mathrm{~N}$, where "h" stands for a heterozygous genotype, " $\mathrm{H}$ " for homozygous genotype and " $\mathrm{N}$ " for the number of samples). Associations between polymorphisms, PD-L1 protein expression, and the clinicopathological parameters of NSCLC patients were investigated by Chi-square test. The prognostic value of each polymorphism was assessed by a survival analysis using the Kaplan-Meier method with the Log rank test for statistical significance. In addition, Cox's proportional hazards regression models were used in a multivariate analysis to test the association between SNPs and PPS and OS. PPS was considered as the period from tumor progression until death or last follow-up. OS was defined as the time from curative surgery to death or last date known to be alive. The statistical software program IBM SPSS (version 22; Armonk, NY, USA) performed all analyses. Differences were considered statistically significant at $P<0.05$.

\section{Results}

\section{Clinicopathologic Characteristics}

Of the 70 patients included in the study, 33 presented with ADC (47.1\%), 24 with SqCC (34.3\%), and 13 with LCC (18.6\%). The clinical characteristics by histologic types are summarized in Table 1. While SqCC cases were more frequent in males (81.8\%), $\mathrm{ADC}$ cases were equally distributed between genders, and LCC cases were close to equal 
Table I Demographic and Clinicopathological Characteristics of 70 NSCLC Patients

\begin{tabular}{|c|c|c|c|c|}
\hline \multirow[t]{2}{*}{ Characteristics } & \multicolumn{3}{|c|}{ Histological Subtypes } & \multirow[t]{2}{*}{$P$-value } \\
\hline & $\begin{array}{l}\text { Adenocarcinoma } \\
(\mathrm{N}=33)\end{array}$ & $\begin{array}{l}\text { Squamous Cell } \\
\text { Carcinoma }(\mathrm{N}=24)\end{array}$ & $\begin{array}{l}\text { Large Cell } \\
\text { Carcinoma }(\mathrm{N}=13)\end{array}$ & \\
\hline $\begin{array}{l}{ }^{\text {a Gender }} \\
\text { Male } \\
\text { Female }\end{array}$ & $\begin{array}{l}10(50.0 \%) \\
10(50.0 \%)\end{array}$ & $\begin{array}{l}9(81.8 \%) \\
2(18.2 \%)\end{array}$ & $\begin{array}{l}5 \text { (55.6\%) } \\
4(44.4 \%)\end{array}$ & 0.21 \\
\hline $\begin{array}{l}{ }^{\text {aAge }} \text { (years) } \\
\quad \leq 63 \\
>63\end{array}$ & $\begin{array}{l}\text { II (61.I\%) } \\
7 \text { (38.9\%) }\end{array}$ & $\begin{array}{l}6(54.5 \%) \\
5(45.5 \%)\end{array}$ & $\begin{array}{l}6(60.0 \%) \\
4(40.0 \%)\end{array}$ & 0.93 \\
\hline $\begin{array}{l}\text { aSmoke Status } \\
\text { Yes } \\
\text { No }\end{array}$ & $\begin{array}{l}8(72.7 \%) \\
3(27.3 \%)\end{array}$ & $\begin{array}{l}8 \text { (88.9\%) } \\
\text { I (11.1\%) }\end{array}$ & $\begin{array}{l}3(50.0 \%) \\
3(50.0 \%)\end{array}$ & 0.25 \\
\hline 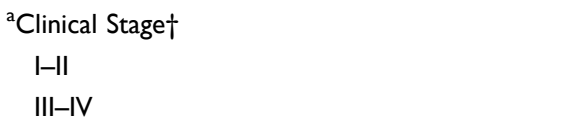 & $\begin{array}{l}8(47.1 \%) \\
9(52.9 \%)\end{array}$ & $\begin{array}{l}4(40.0 \%) \\
6(60.0 \%)\end{array}$ & $\begin{array}{l}3(42.9 \%) \\
4(57.1 \%)\end{array}$ & 0.93 \\
\hline $\begin{array}{l}{ }^{\text {a}} \text { Treatment } \\
\text { Chemotherapy } \\
\text { Yes } \\
\text { No }\end{array}$ & $\begin{array}{l}7(36.8 \%) \\
12(63.2 \%)\end{array}$ & $\begin{array}{l}3(27.3 \%) \\
8(72.7 \%)\end{array}$ & $\begin{array}{l}4(40.0 \%) \\
6(60.0 \%)\end{array}$ & 0.80 \\
\hline $\begin{array}{l}\text { Radiotherapy } \\
\text { Yes } \\
\text { No }\end{array}$ & $\begin{array}{l}\text { I }(5.3 \%) \\
\text { I8 (94.7\%) }\end{array}$ & $\begin{array}{l}\text { I (9.1\%) } \\
10(90.9 \%)\end{array}$ & $\begin{array}{l}0(0.0 \%) \\
10(100 \%)\end{array}$ & 0.63 \\
\hline $\begin{array}{l}{ }^{\text {a Relapse }} \\
\text { Yes } \\
\text { No }\end{array}$ & $\begin{array}{l}9(64.3 \%) \\
5(35.7 \%)\end{array}$ & $\begin{array}{l}4(50.0 \%) \\
4(50.0 \%)\end{array}$ & $\begin{array}{l}2(33.3 \%) \\
4(66.7 \%)\end{array}$ & 0.43 \\
\hline 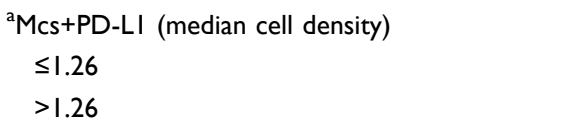 & $\begin{array}{l}\text { I3 (54.2\%) } \\
\text { II (45.8\%) }\end{array}$ & $\begin{array}{l}10(52.6 \%) \\
9(47.4 \%)\end{array}$ & $\begin{array}{l}3(30.0 \%) \\
7(70.0 \%)\end{array}$ & 0.40 \\
\hline $\begin{array}{l}\text { Follow-up (months) } 66 \text { ( } 12-144) \\
\text { aPatients censored for survival analysis at last } \\
\text { follow-up time }\end{array}$ & $8(53.3 \%)$ & $4(66.7 \%)$ & $3(42.9 \%)$ & - \\
\hline
\end{tabular}

Notes: a'Some cases had missing follow-up information: gender (30); age (3I); smoke status (44); clinical stage (36); adjuvant treatment QT/RT (30); relapse (42); Mcs+PD-LI (17); survival (44). $†$ 8th International Association for the Study of Lung Cancer [23].

Abbreviations: Mcs, malignant cells; PD-LI, programmed death-ligand I.

distribution (male 55.6\%, female 44.4\%). All histological types were more frequent in patients aged 63 years or younger. 8 patients reported a history of tobacco smoking in the ADC group (72.7\%) and in the $\mathrm{SqCC}$ group $(88.9 \%)$, versus 3 patients in the LCC group (50.0\%). All the histological subtypes included advanced stages of disease ( 9 cases in ADC, 6 cases in SqCC, and 4 cases in LCC). Most of the patients had not received either chemotherapy ( 12 cases to $\mathrm{ADC}, 8$ cases to $\mathrm{SqCC}$, and 6 cases to $\mathrm{LCC}$ ) or radiation therapy (18 cases to $\mathrm{ADC}, 10$ cases to $\mathrm{SqCC}$, and $\mathrm{LCC}$ ) as adjuvant treatment. Malignant cells expressed PD-L1 above the median in 7 LCC cases $(70.0 \%)$, the most relevant expression compared to the other two histological subtypes. The median follow-up was 66 (12-144) months. None of the analysis revealed significant differences between histological types $(P>0.05)$.

\section{Allele and Genotype Distributions of PD-LI Gene Polymorphisms}

All NSCLC patients who underwent surgical resection were successfully genotyped for fifteen $P D-L 1$ SNPs: rs $76805387 \mathrm{~T}>\mathrm{C}, \quad$ rs $4742098 \mathrm{~A}>\mathrm{G}, \quad$ rs $47946526 \mathrm{~A}>\mathrm{G}$, rs $10217310 \mathrm{G}>\mathrm{T}, \quad \mathrm{rs} 7864231 \mathrm{G}>\mathrm{A}, \quad \mathrm{rs} 41280725 \mathrm{C}>\mathrm{T}$, rs $573692330 \mathrm{~A}>\mathrm{G}, \quad$ rs $1011769981 \mathrm{G}>\mathrm{A}, \quad \mathrm{rs} 41280723 \mathrm{~T}>\mathrm{C}$, rs138135676T $>C, \quad r s 4143815 \mathrm{G}>C, \quad r s 2297136 \mathrm{G}>\mathrm{A}$, 
rs $148242519 \mathrm{G}>\mathrm{A}$, rs $41303227 \mathrm{C}>\mathrm{T}$, and $\mathrm{rs} 7041009 \mathrm{G}>\mathrm{A}$. Supplementary Table 1 shows the SNP identification numbers, allele and genotype frequencies, and $P$-value for HWE. Of the 15 SNPs studied, 11 were found to be monomorphic, whereas 4 SNPs, namely rs4742098, rs4143815, rs2297136, and rs7041009, were polymorphic in NSCLC. Monomorphic SNPs were excluded from further analysis. All the polymorphic SNPs were found to be in equilibrium $(\mathrm{P}>0.05)$ for HWE. The allele frequency of our cohort was compared to different populations in the 1000 Genomes Project (Supplementary Table 2).
Correlation Between PD-LI Gene Polymorphisms and Clinicopathological Characteristics in NSCLC

We performed stratified analyses on the associations between clinical characteristics and the four $P D-L 1$ polymorphisms with different genotypic distributions. Table 2 shows each SNP genotype frequency and their associated clinicopathological characteristics. Three of the four $P D$ L1 gene polymorphisms (rs4742098, rs4143815, and rs7041009) were significantly associated with relapse

Table 2 Clinicopathological Characteristics of 70 NSCLC Patients Stratified by the PD-LI Polymorphisms rs4742098, rs4I438I5, rs2297136 and rs7041009

\begin{tabular}{|c|c|c|c|c|c|c|c|c|c|c|c|c|}
\hline \multirow[t]{3}{*}{ Characteristics } & \multicolumn{3}{|c|}{ rs4742098 AA vs AG/GG } & \multicolumn{3}{|c|}{ rs4I438I5 GG vs CG/CC } & \multicolumn{3}{|c|}{ rs2297।36 GG vs AG/AA } & \multicolumn{3}{|c|}{ rs7041009 GG vs AG/AA } \\
\hline & \multicolumn{3}{|c|}{ No. of Patients $(\mathrm{N}=70)(\%)$} & \multicolumn{3}{|c|}{ No. of Patients $(\mathrm{N}=70)(\%)$} & \multicolumn{3}{|c|}{ No. of Patients $(\mathrm{N}=70)(\%)$} & \multicolumn{3}{|c|}{ No. of Patients $(\mathrm{N}=70)(\%)$} \\
\hline & $\mathbf{A} / \mathbf{A}$ & $\mathbf{A} / \mathbf{G}+\mathbf{G} / \mathbf{G}$ & $P$ & G/G & $\mathbf{C} / \mathbf{G}+\mathbf{C} / \mathbf{C}$ & $P$ & $\mathbf{G} / \mathbf{G}$ & AG+A/A & $P$ & $\mathbf{G} / \mathbf{G}$ & $\mathbf{A} / \mathbf{G}+\mathbf{A} / \mathbf{A}$ & $P$ \\
\hline \multicolumn{13}{|l|}{ Age (years), median } \\
\hline$\leq 63$ & $13(56.5 \%)$ & $10(62.5 \%)$ & 0.75 & II (57.9\%) & $12(60.0 \%)$ & 1.00 & $4(57.1 \%)$ & 19 (59.4\%) & 1.00 & $16(76.2 \%)$ & 7 (38.9\%) & 0.02 \\
\hline$>63$ & $10(43.5 \%)$ & $6(37.5 \%)$ & & $8(42.1 \%)$ & $8(40.0 \%)$ & & $3(42.9 \%)$ & $13(40.6 \%)$ & & $5(23.8 \%)$ & II (6I.1\%) & \\
\hline \multicolumn{13}{|l|}{ Gender, n (\%) } \\
\hline Male & $13(56.5 \%)$ & II (64.7\%) & 0.74 & $12(63.2 \%)$ & $12(57.1 \%)$ & 0.75 & $4(57.1 \%)$ & $20(60.6 \%)$ & 1.00 & $12(57.1 \%)$ & $12(63.2 \%)$ & 0.75 \\
\hline Female & $10(43.5 \%)$ & $6(35.3 \%)$ & & $7(36.8 \%)$ & 9 (42.9\%) & & $3(42.9 \%)$ & $13(39.4 \%)$ & & $9(42.9 \%)$ & $7(36.8 \%)$ & \\
\hline \multicolumn{13}{|l|}{ Smoke status } \\
\hline Yes & $10(71.4 \%)$ & $9(75.0 \%)$ & 1.00 & $9(75.0 \%)$ & $10(7 \mid .4 \%)$ & 1.00 & $4(66.7 \%)$ & $15(75.0 \%)$ & 1.00 & $9(60.0 \%)$ & 10 (90.9\%) & 0.17 \\
\hline No & $4(28.6 \%)$ & $3(25.0 \%)$ & & $3(25.0 \%)$ & $4(28.6 \%)$ & & $2(33.3 \%)$ & $5(25.0 \%)$ & & $6(40.0 \%)$ & I (9.1\%) & \\
\hline \multicolumn{13}{|l|}{ Histology } \\
\hline$A D C$ & 18 (43.9\%) & 15 (51.7\%) & 0.61 & 15 (4I.7\%) & 18 (52.9\%) & 0.40 & 7 (53.8\%) & $26(45.6 \%)$ & 0.86 & $15(41.7 \%)$ & 18 (55.9\%) & 0.34 \\
\hline $\mathrm{SqCC}$ & $16(39.0 \%)$ & $8(27.6 \%)$ & & 15 (41.7\%) & 9 (26.5\%) & & $4(30.8 \%)$ & $20(35.1 \%)$ & & $12(33.3 \%)$ & $12(35.3 \%)$ & \\
\hline LCC & 7 (I7.1\%) & $6(20.7 \%)$ & & $6(16.7 \%)$ & 7 (20.6\%) & & $2(15.4 \%)$ & II (I6.3\%) & & $9(25.0 \%)$ & $4(11.8 \%)$ & \\
\hline \multicolumn{13}{|l|}{ Clinical stage $\dagger$} \\
\hline I-II & $8(40.0 \%)$ & 7 (50.0\%) & 0.72 & 7 (4I.2\%) & 8 (47.1\%) & 1.00 & I (14.3\%) & 14 (5I.9\%) & 0.10 & 8 (44.4\%) & 7 (43.8\%) & 1.00 \\
\hline III-IV & $12(60.0 \%)$ & 7 (50.0\%) & & $10(58.8 \%)$ & 9 (52.9\%) & & $6(85.7 \%)$ & $13(48.1 \%)$ & & $10(55.6 \%)$ & 9 (56.3\%) & \\
\hline \multicolumn{13}{|l|}{ Mcs+PD-LI (median) } \\
\hline$\leq 1.26$ & 15 (57.7\%) & II (42.3\%) & 0.78 & 14 (53.8\%) & 12 (46.2\%) & 1.00 & $6(23.1 \%)$ & 20 (76.9\%) & 0.74 & II (42.3\%) & 15 (57.7\%) & 0.27 \\
\hline$>1.26$ & 14 (5I.9\%) & $13(48.1 \%)$ & & 14 (5।.9\%) & $13(48.1 \%)$ & & 5 (18.5\%) & 22 (8I.5\%) & & 16 (59.3\%) & II (40.7\%) & \\
\hline \multicolumn{13}{|l|}{ Chemotherapy } \\
\hline Yes & 7 (30.4\%) & 7 (4I.2\%) & 0.52 & 5 (26.3\%) & $9(42.9 \%)$ & 0.33 & $3(42.9 \%)$ & II (33.3\%) & 0.67 & $10(47.6 \%)$ & $4(21.1 \%)$ & 0.10 \\
\hline No & $16(69.6 \%)$ & 10 (58.8\%) & & 14 (73.7\%) & $12(57.1 \%)$ & & 4 (57.1\%) & 22 (66.7\%) & & II (52.4\%) & 15 (78.9\%) & \\
\hline \multicolumn{13}{|l|}{ Radiotherapy } \\
\hline Yes & I (4.3\%) & I (5.9\%) & 1.00 & I (5.3\%) & I (4.8\%) & 1.00 & I (14.3\%) & I (3.00\%) & 0.32 & $0(0.0 \%)$ & 2 (10.5\%) & 0.21 \\
\hline No & 22 (95.7\%) & 16 (94.1\%) & & I 8 (94.7\%) & $20(95.2 \%)$ & & $6(85.7 \%)$ & $32(97.0 \%)$ & & $21(100.0 \%)$ & 17 (89.5\%) & \\
\hline \multicolumn{13}{|l|}{ Relapse } \\
\hline Yes & II (78.6\%) & 4 (28.6\%) & 0.01 & 9 (75.0\%) & $6(37.5 \%)$ & 0.05 & 5 (7I.4\%) & $10(47.6 \%)$ & 0.39 & 5 (33.3\%) & 10 (76.9\%) & 0.02 \\
\hline No & 3 (21.4\%) & 10 (71.4\%) & & $3(25.0 \%)$ & $10(62.5 \%)$ & & $2(28.6 \%)$ & II (52.4\%) & & $10(66.7 \%)$ & 3 (23.1\%) & \\
\hline \multicolumn{13}{|l|}{ Status } \\
\hline Live & 5 (38.5\%) & $8(53.3 \%)$ & 0.47 & 5 (45.5\%) & 8 (47.1\%) & 1.00 & $3(50.0 \%)$ & 10 (45.5\%) & 1.00 & II (78.6\%) & 2 (14.3\%) & 0.00 \\
\hline Dead & 8 (61.5\%) & 7 (46.7\%) & & $6(54.5 \%)$ & 9 (52.9\%) & & $3(50.0 \%)$ & 12 (54.5\%) & & $3(21.4 \%)$ & 12 (85.7\%) & \\
\hline
\end{tabular}

Notes: Bolded values are statically significant. †8th International Association for the Study of Lung Cancer [23].

Abbreviations: ADC, adenocarcinoma; SqCC, squamous cell carcinoma; LCC, large cell carcinoma; Mcs, malignant cells; PD-LI, programmed death-ligand I. 
( $P=0.01 ; P=0.05 ; P=0.02$, respectively). For the rs 4742098 variant, carriers of the $\mathrm{G}$ allele (AG or $\mathrm{GG}$ genotypes) were less likely to relapse $(P=0.01)$. Similarly, for rs4143815, carriers of the alternative $C$ allele (CG or CC genotypes) were also less likely to relapse $(P=0.05)$. In rs7041009, however, carriers of the alternative allele A (AG or GG genotypes) were more likely to relapse $(P=0.02)$. Moreover, GG genotype (reference) of rs7041009 showed a significant correlation with age, being more prevalent among younger patients (16 patients, or $69.6 \%$ ), and status, being more prevalent among patients who were alive (11 patients, or $84.6 \%$ ), compared to carriers of the A allele $(P=0.02$ and $P<0.01$, respectively). No statistical significance was observed in the association between rs2297136 genotypes and clinicopathological variants.

\section{Correlation Between PD-LI Gene Polymorphisms and PD-LI Protein Expression}

The correlation between PD-L1 protein expression and $P D$ L1 gene polymorphisms are shown in Table 2. There were no statistically significant associations between PD-L1 protein expression in malignant cells and $P D-L 1$ gene polymorphisms. In our cohort, the four $P D-L 1$ gene polymorphisms were in non-coding regions and, apparently, cause no interference in PD-L1 protein expression in NSCLC malignant cells. However, when we correlated PD-L1 protein expression with histological subtype, we observed that the expression in malignant cells was above the median in $70 \%$ of patients with LLC, in contrast with $45.8 \%$ and $47.4 \%$ of patients with $\mathrm{ADC}$ and $\mathrm{SqCC}$, respectively.

\section{Associations Between PD-LI Gene Polymorphisms and Survival Outcomes}

Our first statistical test examined the individual effect of patients' characteristics to estimate statistical differences in survival using the Kaplan-Meier method (Table 3). Patients younger than 63 years showed increased OS, 111.62 vs 66.54 months in older patients $(P=0.05)$. Choice of treatment was also an independent factor in diagnosis, with patients who did not receive radiotherapy presenting a better survival rate when compared with those who were treated with radiotherapy, 94.43 vs 12.00 months, respectively $(P<0.01)$. Patients who presented disease recurrence had lower survival rates and poorer
Table 3 A Survival Analysis Conducted by the Kaplan-Meier Method Showing the Difference in the Means of the Log Rank Test According to the Optimal Upper and Lower Binary Cut-off Limits of Different Variables

\begin{tabular}{|c|c|c|c|c|}
\hline \multirow[t]{2}{*}{ Variables } & \multicolumn{2}{|c|}{$\begin{array}{l}\text { Overall Survival } \\
\text { (Months) }\end{array}$} & \multirow[t]{2}{*}{$\begin{array}{l}\text { Chi-Square } \\
\text { (Log Rank) }\end{array}$} & \multirow[t]{2}{*}{$P$-value } \\
\hline & Mean & $\begin{array}{l}\text { Standard } \\
\text { Error }\end{array}$ & & \\
\hline \multicolumn{5}{|l|}{ Age } \\
\hline$\leq 63$ & 111.62 & 13.92 & 3.88 & 0.05 \\
\hline$>63$ & 66.54 & 15.99 & & \\
\hline \multicolumn{5}{|l|}{ Treatment } \\
\hline \multicolumn{5}{|l|}{ Radiotherapy } \\
\hline Yes & 12.00 & 0.00 & 11.46 & $<0.01$ \\
\hline No & 94.43 & 11.31 & & \\
\hline \multicolumn{5}{|l|}{ Relapse } \\
\hline Yes & 48.23 & 9.84 & 11.01 & $<0.01$ \\
\hline No & 123.10 & 13.48 & & \\
\hline \multicolumn{5}{|c|}{ PD-LI polymorphisms } \\
\hline \multirow{2}{*}{\multicolumn{5}{|c|}{$\begin{array}{l}\text { rs7041009 (GG vs } \\
\text { AG/AA genotype) }\end{array}$}} \\
\hline & & & & \\
\hline GG & 116.93 & 13.81 & 7.49 & $<0.01$ \\
\hline AG/AA & 59.00 & 13.67 & & \\
\hline
\end{tabular}

Note: Bolded values are statically significant. Abbreviation: PD-LI, programmed death-ligand I.

prognostic when compared with those who did not relapse, 48.23 vs 123.10 months, respectively $(P<0.01)$.

Moreover, differences in the genotypes of $P D-L 1$ polymorphisms seemed to also impact the prognosis of NSCLC patients. $P D-L 1$ rs7041009, for instance, led to a statistically significant difference in OS (Figure 1), with carriers of the A allele of rs 7041009 having lower OS than carriers of the GG genotype (reference), 59.00 vs 116.93 months, respectively $(P<0.01)$.

Next, using a univariate Cox Regression analysis, we were able to associate the following variables with a lower risk of death: the absence of radiotherapy treatment, relapse, and GG genotype of PDL1 rs7041009 (Table 4). However, after feeding these variables into a multivariate analysis, only the absence of radiotherapy treatment and relapse were considered to be independent factors for OS (HR 9.82, $P=0.02$; HR 6.15, $P=0.04$, respectively).

Then, we introduced the $P D-L 1$ polymorphisms into the Cox model, controlling for radiotherapy treatment and tumor relapse. Of the four SNPs, only rs7041009 was identified as a co-dependent factor associated with radiotherapy and relapse. We thus inferred that patients with NSCLC who 


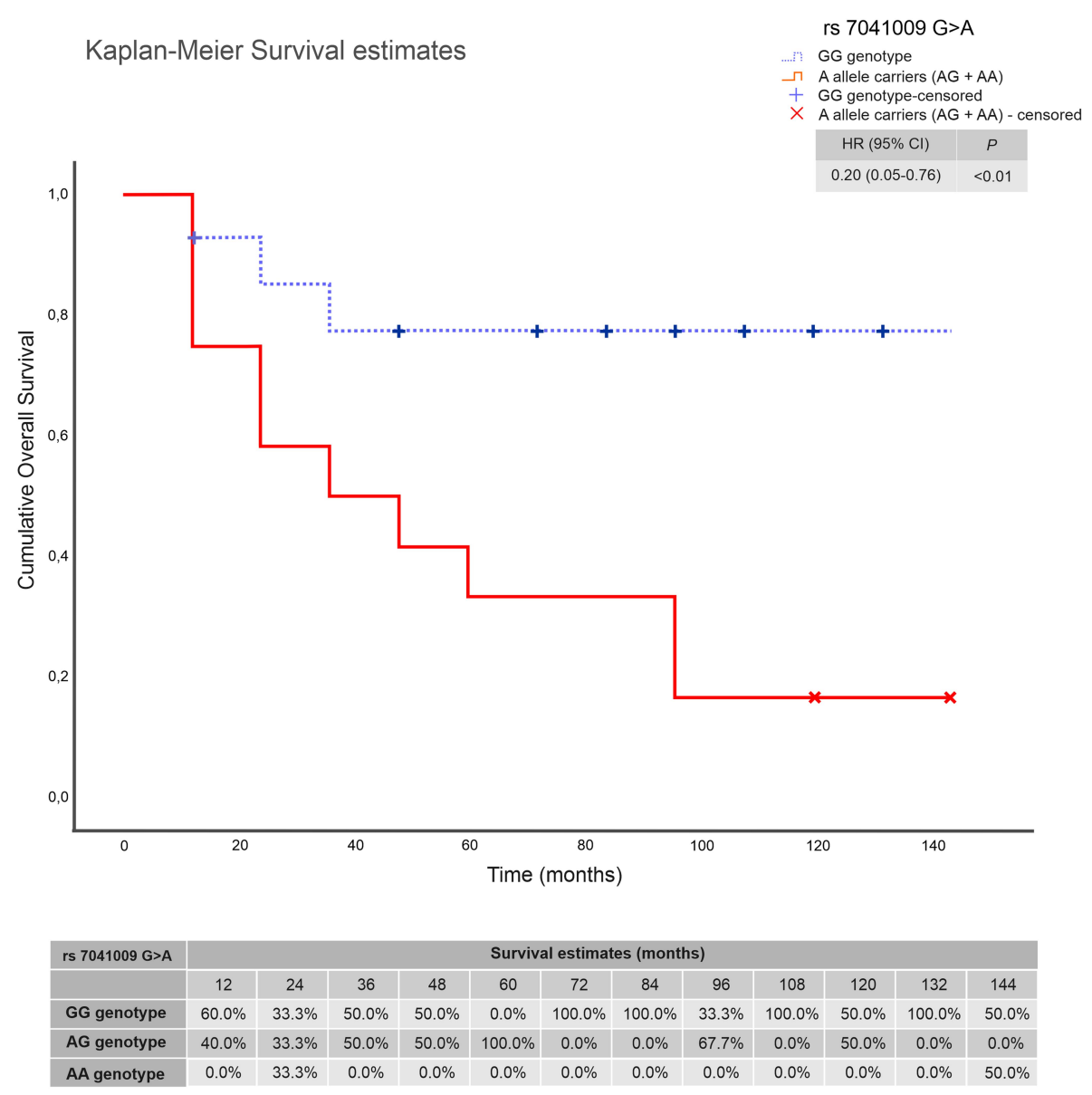

Figure I Kaplan-Meier survival curve for PD-LI rs7041009 G>A. A allele carriers (AG+AA) presented worse prognosis and a lower survival rate when compared to GG genotyped patients $(P<0.01)$.

carried the $\mathrm{A}$ allele (AG/AA) presented a higher risk of relapse in the presence of radiotherapy, resulting in a poorer prognosis and decreased survival rates than patients who carried the rs7041009 GG genotype. In relapsed patients, we observed that the $P D-L 1$ polymorphisms rs7041009 and rs4742098 might have an impact on PPS (Figure 2). Patients with the rs7041009 GG genotype had a higher PPS than those with the alternative A allele of rs7041009 (AG/AA), 110.98 vs 56.18 months, respectively $(P<0.01)$; whereas, patients who carried the reference rs4742098 AA genotype had lower PPS than those who carried the alternative $\mathrm{G}$ allele of rs4742098 (AG/ GG), 56.00 vs 115.71 months, respectively $(P=0.02)$.

\section{In silico Prediction of PD-LI Gene Polymorphisms}

The in silico analysis predicted the $P D-L 1$ variants rs 4742098 (c.*2635A $>$ G), rs4143815 (c.*395G>C), rs2297136 (c. $* 93 \mathrm{G}>\mathrm{A})$, and rs7041009 (c.682+122G $>A$ ) to be benign (Table 5). Not only was the DANN score low for all four variants $(0.8226,0.6475,0.7056$, and 0.5428 , respectively), but their GERP score was also lower than $5.5(-1.74,2.38,4.4$, and 1.81, respectively), indicating that these variants are found in non-conserved positions and are unlikely to be harmful.

SNPinfo predicted miRNA-binding function to be affected by two of these variants, namely rs2297136 and rs 4143815 . Rs2297136 was predicted to affect the binding function of hsamiR-324-5p and hsa-miR-632, whereas rs 4143815 was found to correlate with hsa-miR-1252, hsa-miR-1253, hsa-miR-539, hsa-miR-548, and hsa-miR-570 (Table 6). RegulomeDB was then used to complement the SNP analysis. Three of the four SNPs, rs4742098, rs4143815, and rs2297136, had a RegulomeDB score of 5, whereas rs7041009 had a score of 6 , meaning that all four variants show minimal binding evidence (Table 5).

\section{Discussion}

Lung cancer has a high mortality rate and lacks suitable markers for early diagnosis and prognosis. Thus, it is essential to detect the best potential biomarker out of the several genetic and protein markers. Fortunately for 
Table 4 Variables Associated with Overall Survival (OS) in 70 Patients Diagnosed with NSCLC. Univariate and Multivariate Analyses Employing a Cox Proportional Hazards Model

\begin{tabular}{|c|c|c|c|c|c|}
\hline \multirow[t]{2}{*}{ Clinicopathological Characteristics } & \multicolumn{3}{|c|}{ Univariate Analysis } & \multicolumn{2}{|c|}{ Multivariate Analysis } \\
\hline & HR (95\% Cl) & HR & $P$ value & $\operatorname{HR}^{\mathrm{c}}(95 \% \mathrm{Cl})$ & $P$-value \\
\hline Age (yrs): $\leq 63$ vs $>63$ & $0.33(0.10-1.10)$ & -1.10 & 0.07 & & \\
\hline \multicolumn{6}{|l|}{ Gender } \\
\hline Male & $1.83(0.54-6.14)$ & 0.60 & 0.32 & & \\
\hline \multicolumn{6}{|l|}{ Smoke status } \\
\hline Yes & $1.33(0.33-5.36)$ & 0.28 & 0.68 & & \\
\hline \multicolumn{6}{|l|}{ Histology } \\
\hline ADC & $1.25(0.32-4.86)$ & 0.22 & 0.74 & & \\
\hline $\mathrm{SqCC}$ & $1.67(0.33-8.37)$ & 0.51 & 0.53 & & \\
\hline LCC (reference) & - & - & 0.82 & & \\
\hline \multicolumn{6}{|l|}{ Clinical stage $\dagger$} \\
\hline I-II & $0.4 \mathrm{I}(0.1 \mathrm{I}-\mathrm{I} .52)$ & -0.87 & 0.18 & & \\
\hline III-IV (reference) & - & - & - & & \\
\hline \multicolumn{6}{|l|}{ Therapy } \\
\hline Chemotherapy & $0.36(0.10-1.34)$ & -1.00 & 0.13 & & \\
\hline Yes & & & & & \\
\hline Relapse & $8.47(1.8 I-39.62)$ & 2.13 & 0.00 & $6.15(1.03-36.44)$ & 0.04 \\
\hline Yes & & & & & \\
\hline \multicolumn{6}{|l|}{ Immune checkpoint } \\
\hline $\mathrm{PD}-\mathrm{LI}+/ \mathrm{mm}^{2}$ & $1.00(0.95-1.05)$ & 0.00 & 0.94 & & \\
\hline \multicolumn{6}{|l|}{ polymorphisms in PD-LI } \\
\hline \multicolumn{6}{|l|}{ rs4742098 } \\
\hline AA genotype & $2.02(0.65-6.30)$ & 0.70 & 0.22 & & \\
\hline G allele carrier (reference) & - & - & - & & \\
\hline \multicolumn{6}{|l|}{ rs4 I438 I 5} \\
\hline GG genotype & $1.58(0.52-4.81)$ & 0.46 & $0.4 \mathrm{I}$ & & \\
\hline $\mathrm{C}$ allele carrier (reference) & - & - & - & & \\
\hline \multicolumn{6}{|l|}{ rs2297I36 } \\
\hline GG genotype & $1.24(0.34-4.55)$ & 0.22 & 0.73 & & \\
\hline A allele carrier (reference) & - & - & - & & \\
\hline \multicolumn{6}{|l|}{ rs7041009 } \\
\hline GG genotype & $0.20(0.05-0.76)$ & -1.56 & 0.01 & $0.57(0.12-2.70)$ & 0.48 \\
\hline A allele carrier (reference) & - & - & - & & \\
\hline
\end{tabular}

Notes: Bolded values are statically significant. †8th International Association for the Study of Lung Cancer [23].

Abbreviations: ADC, adenocarcinoma; SqCC, squamous cell carcinoma; LCC, large cell carcinoma; HR, hazard ratio ( $\beta$ coefficient); Cl, confidence interval; PD-LI, programmed death-ligand I.

patients, the translational impact of such findings is rapidly increasing, and the stimulation of immune response by ICIs has emerged as a dramatic paradigm shift in the treatment of advanced tumors, mainly NSCLC. ${ }^{19,36}$ PD1/PD-L1 monoclonal antibodies have shown potential efficacy in advanced squamous-cell and non-squamous
NSCLC. ${ }^{37,38}$ However, despite the remarkable success achieved by immunotherapy so far, its effectiveness still seems to vary among cancer patients. ${ }^{19}$ The expression of PD-L1 on tumor cells remains the only recognized predictive factor for immunotherapy response in NSCLC patients; however, patients without PD-L1 expression on 

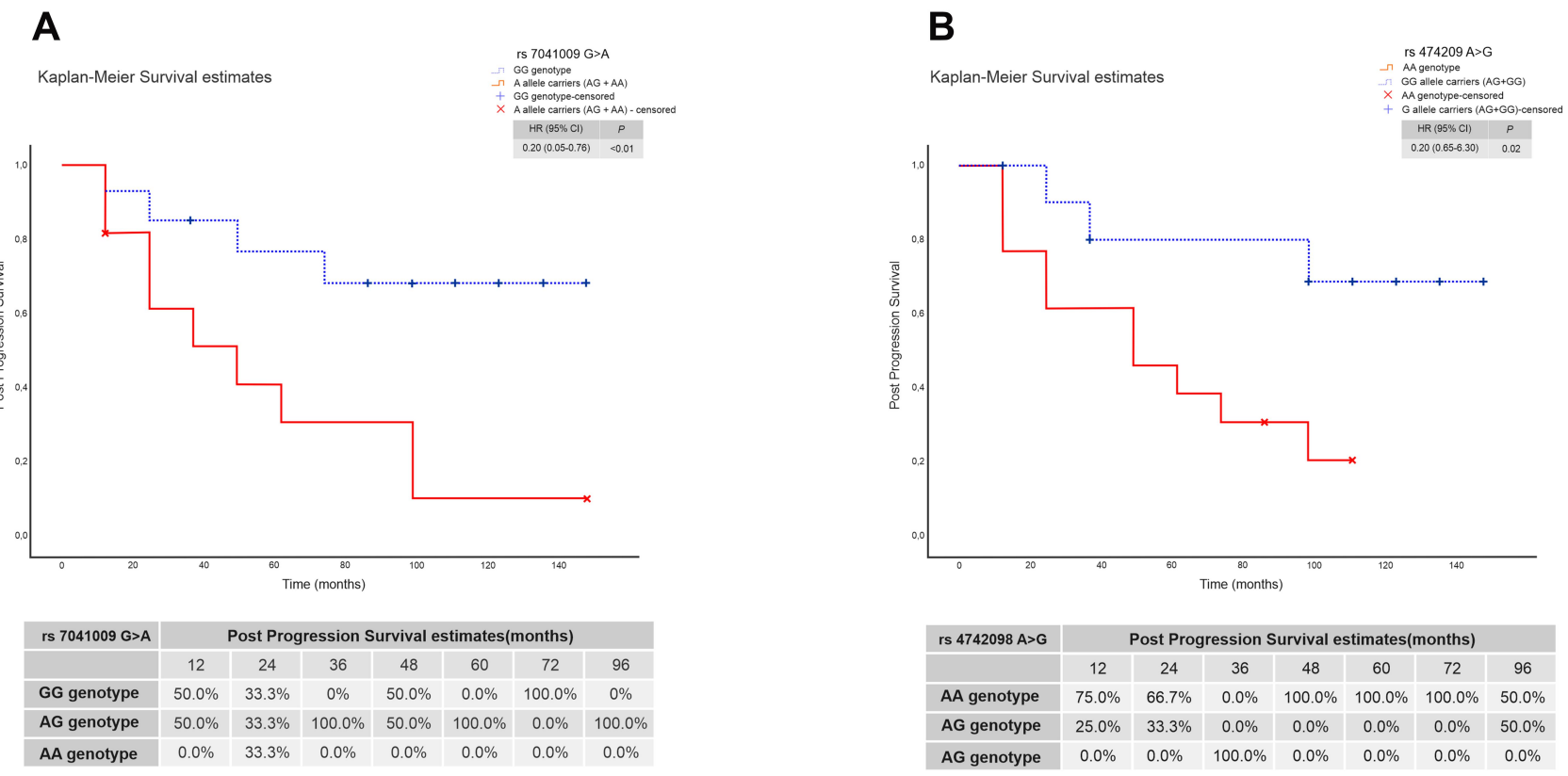

Figure 2 Kaplan-Meier survival curves estimating post-progression survival (PPS) in NSCLC patients according to PD-LI polymorphisms. (A) Kaplan-Meier survival curve for rs7041009 G>A. A allele carriers (AG+AA) presented worse prognosis and a lower PPS rate when compared GG genotyped patients $(P<0.01)$; $(B)$ Kaplan-Meier survival curve for rs $4742098 A>G$. $G$ allele carriers $(A G+G G)$ had a higher PPS rate and better prognosis when compared $A A$ genotyped patients $(P=0.02)$.

tumor cells may also respond to immunotherapy. ${ }^{39-43}$ Based on these findings, the present study inferred that $P D-L 1$ non-coding genetic variants could help predict the prognosis of patients with NSCLC and impact disease recurrence and OS.

In our cohort of 70 NSCLC specimens, we evaluated PD-L1 protein expression in malignant cells by PD-L1 multiplex immunofluorescence (mIF) assays, using the Cell Signaling E1L3N clone and image analysis, and investigated $P D-L 1$ polymorphisms by NGS sequencing. This method resulted in the detection of high PD-L1 expression in LCC malignant cells when compared to other histological subtypes, suggesting that LCC patients may benefit from ICIs. As described by Shimoji et al, ${ }^{44}$ PD-L1 expression using the Cell Signaling E1L3N clone was significantly correlated with a consistent vimentin expression, increased $\mathrm{Ki}-67$ labeling index and poor prognosis in ADC but not in SqCC. Other studies have reported that $\mathrm{PD}-\mathrm{L} 1$ was detected at significantly higher frequencies in SqCC than in ADC of the lung. ${ }^{44,45}$ Cha et $\mathrm{al}^{46}$ found that PD-L1 expression using the SP142 clone was significantly associated with an ADC solid subtype histology, p53 aberrant expression, and poor prognosis.

We also assessed $P D-L 1$ polymorphisms. Of the fifteen genetic variants genotyped, eleven were monomorphic. The four potential variants (rs4742098, rs4143815, rs2297136, and rs7041009) present in the non-coding region were correlated with the clinicopathological characteristics of the NSCLC patients and were submitted to an in silico analysis investigating their functional role. The MAF of the rs4742098, rs4143815, and rs7041009 polymorphisms was consistent with the genotype frequency among European and Mixed Americans populations present in The 1000 Genomes Project, whereas the G allele in

Table 5 List of the Selected Non-Coding SNP and the Tools Used to Study Them

\begin{tabular}{|l|l|l|l|l|}
\hline dbSNP ID & Region & FuncPred & RegulomeDB score & VarSome (DANN Score) \\
\hline rs4742098 & $3^{\prime}$ UTR & - & 5 & Benign (0.8226) \\
rs4143815 & $3^{\prime} U T R$ & miRNA-binding function & 5 & Benign (0.6475) \\
rs2297I36 & $3^{\prime} U T R$ & miRNA-binding function & 5 & Benign (0.7056) \\
rs7041009 & Intron & - & 6 & Benign (0.5428) \\
\hline
\end{tabular}

Note: SNPs that do not affect function.

Abbreviations: SNPs, single-nucleotide polymorphisms; dbSNP, SNP database; FuncPred, SNP function prediction; RegulomeDB score, RegulomeDB variant classification; VarSome, The human genomics community; DANN score, annotation of genetic variants using neural networks. 
Table 6 List of the 3' UTR SNPs Analyzed in FuncPred and Their miRNA Motif

\begin{tabular}{|l|l|l|}
\hline dbSNP ID & Allele & miRNA Motif \\
\hline rs4I438I5 & C & hsa-miR-I252 \\
& C & hsa-miR-I253 \\
& C & hsa-miR-539 \\
& C & hsa-miR-548 \\
& G & hsa-miR-570 \\
\hline rs2297I36 & A/G & hsa-miR-324-5p \\
& A/G & hsa-miR-632 \\
\hline
\end{tabular}

Abbreviations: FuncPred, SNP function prediction; dbSNP ID, SNP database identification.

the rs2297136 polymorphism was the main allele in our cohort to show racial differences.

When assessing patient prognosis, three of the four $P D-L 1$ variants rs4742098, rs4143815, and rs7041009 were significantly associated with disease recurrence. Carriers of the $G$ allele (individuals with the $A G$ or $G G$ genotypes) of rs4742098 were less likely to relapse compared to carriers of the homozygous AA genotype. Similar findings were published by $\mathrm{Du}$ and colleagues, ${ }^{47}$ who reported that the AG genotype differed from the AA genotype in terms of risk of NSCLC recurrence. In the case of rs $4143815 \mathrm{G}$, patients with the alternative C allele were less likely to relapse in our study, in agreement with Nomizo et al's report. ${ }^{48}$ In their study, the authors even suggested that this polymorphism might be a biomarker for nivolumab efficacy. ${ }^{48}$ Finally, in our study, for rs7041009G $>A$, carriers of the alternative $G$ allele were more likely to exhibit relapse. The rs 7041009 GG genotype also showed a significant correlation with age, being more present in younger patients, and with status, being more present in patients who are alive, compared to carriers of the A allele. Rs7041009 (c. $682+122 \mathrm{G}>\mathrm{A}$ ) is located at position 2377 in intron 4 of the PD-L1 gene. However, little is known about the exact function of this genetic variation, except that it is located near the transcription factor binding site.

Our cohort showed a significant association between these PD-L1 polymorphisms and OS in NSCLC. 18 Patients presenting the GG genotype of rs 7041009 benefited from longer OS. In addition, our findings indicated that both the rs $7041009 \mathrm{G}$ and rs4742098G polymorphisms were significantly related to a longer PPS. The clinical impacts of $P D-L 1$ variants had also been investigated by previous studies. Zhao et $\mathrm{al}^{49}$ suggested that patients with the GG genotype of another $P D-L 1$ polymorphism (rs822336) had worse disease-free survival and OS in a Chinese patient population.

Further contribution was provided in that respect by Lee et $\mathrm{al}^{50}$ who demonstrated that rs4143815 and rs2297136 were significantly associated with clinical outcomes after chemotherapy. Of 379 patients with NSCLC treated with first-line paclitaxel-cisplatin chemotherapy, those carrying the rs4143815 G allele responded better to chemotherapy and had gains in overall survival. In our study, however, the polymorphism rs2297136 showed no significant association with clinical outcome, a finding that was corroborated by Zhao et al. ${ }^{49}$ This difference might be explained by the heterogeneity of patients enrolled in each study, and further research is needed to settle this question.

In our study, we were unable to find any statistical significance between the rs4742098, rs4143815, rs2297136, and rs7041009 genotypes and PD-L1 protein expression in malignant cells. However, recent data have helped to shed light on the impact of $P D-L 1$ genetics on PDL1 expression, though the existing results remain controversial. Recently, Tao and colleagues ${ }^{51}$ showed that rs4143815 and rs 10815225 in the $P D-L 1$ gene contributed to PD-L1 overexpression in gastric cancer. So far, Lee et a ${ }^{18}$ have conducted the largest study on $P D-L 1$ polymorphisms and PD-L1 expression in NSCLC. The authors showed that rs $822336 \mathrm{C}$, rs $822337 \mathrm{~A}$ and rs4143815G were associated with worse OS in NSCLC patients but found no significant correlation between PD-L1 expression and the genotypes of these polymorphisms. Krawczyk et $\mathrm{al}^{52}$ demonstrated that carriers of the rs $822335 \mathrm{CC}$ genotype were predisposed to higher expression of the PD-L1 protein in NSCLC tumor cells, whereas rs822336 had no effect on PD-L1 expression in these cells. Their results are consistent with our findings, but future research is needed to clarify remaining confounders.

In our study, using in silico approaches, we report that rs4742098, rs4143815, rs2297136, and rs7041009 can be considered benign variants. However, little is known about the effect that mutations in conserved non-coding regions might have on fitness and how many of them are present in the human genome as deleterious polymorphisms. Moreover, rs2297136 was predicted to affect the miRNAbinding function of hsa-miR-324-5p and hsa-miR-632, whereas the variant rs4143815 was found to correlate with hsa-miR-1252, hsa-miR-1253, hsa-miR-539, hsamiR-548, and hsa-miR-570. In this context, others have 
reported that variants in the $3^{\prime} \mathrm{UTR}$ region of the $P D-L 1$ gene can affect the interaction of miRNAs, possibly resulting in $P D-L 1$ underexpression. ${ }^{53}$ Therefore, additional studies are necessary to validate our findings. However, there are limitations to our analysis. We did not perform a case-control approach and our cohort comprises a relatively small sample size. Nonetheless, to our knowledge, our research on the effect of the rs7041009 polymorphism of $P D-L 1$ gene on NSCLC patients is unique.

We believe this study is also the first to evaluate variants in the non-coding region of the $P D-L 1$ in Brazilian patients with NSCLC, since most studies of $P D$ L1 polymorphisms have been conducted in Asian patients. Thus, we consider this exploratory study as a pioneer in the understanding of $P D-L 1$ polymorphisms in a genetic admixed population.

\section{Acknowledgments}

We appreciate all subjects who participated in this study and the Illumina members for assistance with the initial runs.

\section{Funding}

This study was supported by the São Paulo Research Foundation, FAPESP (grant numbers 2013/14277-4 and 2018/20403-6).

\section{Disclosure}

The authors report no conflicts of interest related to this work.

\section{References}

1. Shankar A, Saini D, Dubey A, et al. Feasibility of lung cancer screening in developing countries: challenges, opportunities and way forward. Transl Lung Cancer Res. 2019;8(Suppl S1):S106-S121. doi:10.21037/tlcr.2019.03.03

2. Berghmans T, Durieux V, Hendriks LEL, Dingemans A-M. Immunotherapy: from Advanced NSCLC to Early Stages, an Evolving Concept. Front Med. 2020;7:90. doi:10.3389/ fmed.2020.00090

3. Bylicki O, Paleiron N, Rousseau-Bussac G, Chouaïd C. New PDL1 inhibitors for non-small cell lung cancer: focus on pembrolizumab. Onco Targets Ther. 2018;11:4051-4064. doi:10.2147/OTT.S154606

4. Yeo M-K, Choi S-Y, Seong I-O, Suh K-S, Kim JM, Kim K-H. Association of PD-L1 expression and PD-L1 gene polymorphism with poor prognosis in lung adenocarcinoma and squamous cell carcinoma. Hum Pathol. 2017;68:103-111. doi:10.1016/j. humpath.2017.08.016

5. Francisco LM, Salinas VH, Brown KE, et al. PD-L1 regulates the development, maintenance, and function of induced regulatory $\mathrm{T}$ cells. J Exp Med. 2009;206(13):3015-3029. doi:10.1084/jem.20090847
6. Lantuejoul S, Damotte D, Hofman V, Adam J. Programmed death ligand 1 immunohistochemistry in non-small cell lung carcinoma. $J$ Thorac Dis. 2019;11(Suppl S1):S89-S101. doi:10.21037/ jtd.2018.12.103

7. Aggarwal C, Abreu DR, Felip E, et al. Prevalence of PD-L1 expression in patients with non-small cell lung cancer screened for enrollment in KEYNOTE-001, -010, and -024. Ann Oncol. 2016;27 (6):359-378. doi:10.1093/annonc/mdw378.14

8. Yu H, Boyle TA, Zhou C, Rimm DL, Hirsch FR. PD-L1 Expression in Lung Cancer. J Thorac Oncol. 2016;11(7):964-975. doi:10.1016/j. jtho.2016.04.014

9. Reck M, Rodríguez-Abreu D, Robinson AG, et al. Pembrolizumab versus Chemotherapy for PD-L1-Positive Non-Small-Cell Lung Cancer. $N$ Engl J Med. 2016;375(19):1823-1833. doi:10.1056/ NEJMoa1606774

10. Marwitz S, Scheufele S, Perner S, Reck M, Ammerpohl O, Goldmann T. Epigenetic modifications of the immune-checkpoint genes CTLA4 and PDCD1 in non-small cell lung cancer results in increased expression. Clin Epigenetics. 2017;9(1):51. doi:10.1186/ s13148-017-0354-2

11. Chen L, Gibbons DL, Goswami S, et al. Metastasis is regulated via microRNA-200/ZEB1 axis control of tumour cell PD-L1 expression and intratumoral immunosuppression. Nat Commun. 2014;5(1):5241. doi:10.1038/ncomms6241

12. Ma Y, Adjemian S, Mattarollo SR, et al. Anticancer chemotherapy-induced intratumoral recruitment and differentiation of antigen-presenting cells. Immunity. 2013;38(4):729-741. doi:10.1016/j.immuni.2013.03.003

13. Mazzaschi G, Madeddu D, Falco A, et al. Low PD-1 Expression in Cytotoxic CD8 + Tumor-Infiltrating Lymphocytes Confers an Immune-Privileged Tissue Microenvironment in NSCLC with a Prognostic and Predictive Value. Clin Cancer Res. 2018;24 (2):407-419. doi:10.1158/1078-0432.CCR-17-2156

14. de Vooght KMK, van Wijk R, van Solinge WW. Management of Gene Promoter Mutations in Molecular Diagnostics. Clin Chem. 2009;55(4):698-708. doi:10.1373/clinchem.2008.120931

15. Cuykendall TN, Rubin MA, Khurana E. Non-coding genetic variation in cancer. Curr Opin Syst Biol. 2017;1:9-15. doi:10.1016/j. coisb.2016.12.017

16. Amlie-Wolf A, Tang M, Way J, et al. Inferring the Molecular Mechanisms of Noncoding Alzheimer's Disease-Associated Genetic Variants. J Alzheimers Dis. 2019;72(1):301-318. doi:10.3233/JAD190568

17. Hashemi M, Karami S, Sarabandi S, et al. Association between PD-1 and PD-L1 Polymorphisms and the Risk of Cancer: A Meta-Analysis of Case-Control Studies. Cancers. 2019;11(8):1150. doi:10.3390/ cancers 11081150

18. Lee SY, Jung DK, Choi JE, et al. Functional polymorphisms in PD-L1 gene are associated with the prognosis of patients with early stage non-small cell lung cancer. Gene. 2017;599:28-35. doi:10.1016/j.gene.2016.11.007

19. Fabrizio FP, Trombetta D, Rossi A, Sparaneo AA, Castellana S, Muscarella LA. Gene code CD274/PD-L1: from molecular basis toward cancer immunotherapy. Ther Adv Med Oncol. 2018;10:1758835918815598. doi:10.1177/1758835918815598

20. Araujo LH, Baldotto CA, Castro JGD, et al. Lung cancer in Brazil. J Bras Pneumol. 2018;44(1):55-64. doi:10.1590/s1806-3756201 7000000135

21. de Melo AC, de Sá VK, Sternberg C, et al. Mutational Profile and New IASLC/ATS/ERS Classification Provide Additional Prognostic Information about Lung Adenocarcinoma: A Study of 125 Patients from Brazil. Oncology. 2015;89(3):175-186. doi:10.1159/000376552

22. de Sá VK, Coelho JC, Capelozzi VL, de Azevedo SJ. Lung cancer in Brazil: epidemiology and treatment challenges.. Lung Cancer. 2016;7:141-148. doi:10.2147/LCTT.S93604 
23. Goldstraw P, Chansky K, Crowley J, et al. The IASLC Lung Cancer Staging Project: proposals for Revision of the TNM Stage Groupings in the Forthcoming (Eighth) Edition of the TNM Classification for Lung Cancer. J Thorac Oncol. 2016;11(1):39-51. doi:10.1016/j. jtho.2015.09.009

24. Parra ER, Uraoka N, Jiang M, et al. Validation of multiplex immunofluorescence panels using multispectral microscopy for immune-profiling of formalin-fixed and paraffin-embedded human tumor tissues. Sci Rep. 2017;7(1):13380. doi:10.1038/s41598-01713942-8

25. Parra ER, Jiang M, Machado-Rugolo J, et al. Variants in EpithelialMesenchymal Transition and Immune Checkpoint Genes Are Associated With Immune Cell Profiles and Predict Survival in Non-Small Cell Lung Cancer. Arch Pathol Lab Med. 2020;144 (10):1234-1244. doi:10.5858/arpa.2019-0419-OA

26. Gorris MAJ, Halilovic A, Rabold K, et al. Eight-Color Multiplex Immunohistochemistry for Simultaneous Detection of Multiple Immune Checkpoint Molecules within the Tumor Microenvironment. J Immunol. 2018;200(1):347-354. doi:10.4049/ jimmunol.1701262

27. Li H, Durbin R. Fast and accurate short read alignment with Burrows-Wheeler transform. Bioinformatics. 2009;25 (14):1754-1760. doi:10.1093/bioinformatics/btp324

28. McLaren W, Gil L, Hunt SE, et al. The Ensembl Variant Effect Predictor.. Genome Biol. 2016;17(1):122. doi:10.1186/s13059-0160974-4

29. Naslavsky MS, Yamamoto GL, de Almeida TF, et al. Exomic variants of an elderly cohort of Brazilians in the ABraOM database. Hum Mutat. 2017;38(7):751-763. doi:10.1002/humu.23220

30. Kopanos C, Tsiolkas V, Kouris A, et al. VarSome: the human genomic variant search engine. Bioinformatics. 2019;35(11):1978-1980. doi:10.1093/bioinformatics/bty897

31. Quang D, Chen Y, Xie X. DANN: a deep learning approach for annotating the pathogenicity of genetic variants. Bioinformatics. 2015;31(5):761-763. doi:10.1093/bioinformatics/btu703

32. Davydov EV, Goode DL, Sirota M, Cooper GM, Sidow A, Batzoglou S. Identifying a high fraction of the human genome to be under selective constraint using GERP++. PLoS Comput Biol. 2010;6 (12):e1001025. doi:10.1371/journal.pcbi.1001025

33. Cooper GM, et al. Distribution and intensity of constraint in mammalian genomic sequence. Genome Res. 2005;15(7):901-913. doi:10.1101/gr.3577405

34. Xu Z, Taylor JA. SNPinfo: integrating GWAS and candidate gene information into functional SNP selection for genetic association studies. Nucleic Acids Res. 2009;37(suppl_2):W600-W605. doi:10.1093/nar/gkp290

35. Boyle AP, Hong EL, Hariharan M, et al. Annotation of functional variation in personal genomes using RegulomeDB. Genome Res. 2012;22(9):1790-1797. doi:10.1101/gr.137323.112

36. Nishino M, Ramaiya NH, Hatabu H, Hodi FS. Monitoring immune-checkpoint blockade: response evaluation and biomarker development. Nat Rev Clin Oncol. 2017;14(11):655-668. doi:10.1038/nrclinonc.2017.88

37. Borghaei H, Paz-Ares L, Horn L, et al. Nivolumab versus Docetaxel in Advanced Nonsquamous Non-Small-Cell Lung Cancer. $N$ Engl J Med. 2015;373(17):1627-1639. doi:10.1056/NEJMoa1507643

38. Brahmer J, Reckamp KL, Baas P, et al. Nivolumab versus Docetaxel in Advanced Squamous-Cell Non-Small-Cell Lung Cancer. $N$ Engl $J$ Med. 2015;373(2):123-135. doi:10.1056/NEJMoa1504627

39. Yi C, He Y, Xia H, Zhang H, Zhang P. $<$ p $>$ Review and perspective on adjuvant and neoadjuvant immunotherapies in NSCLC. Onco Targets Ther. 2019;12:7329-7336. doi:10.2147/OTT.S218321
40. Horn L, Spigel DR, Vokes EE, et al. Nivolumab Versus Docetaxel in Previously Treated Patients With Advanced Non-Small-Cell Lung Cancer: two-Year Outcomes From Two Randomized, Open-Label, Phase III Trials (CheckMate 017 and CheckMate 057). J Clin Oncol. 2017;35(35):3924-3933. doi:10.1200/JCO.2017.74.3062

41. Antonia SJ, Villegas A, Daniel D, et al. Durvalumab after Chemoradiotherapy in Stage III Non-Small-Cell Lung Cancer. $N$ Engl J Med. 2017;377(20):1919-1929. doi:10.1056/ NEJMoa1709937

42. Fehrenbacher L, von Pawel J, Park K, et al. Updated Efficacy Analysis Including Secondary Population Results for OAK: A Randomized Phase III Study of Atezolizumab versus Docetaxel in Patients with Previously Treated Advanced Non-Small Cell Lung Cancer. J Thorac Oncol. 2018;13(8):1156-1170. doi:10.1016/j. jtho.2018.04.039

43. Gandhi L, Rodríguez-Abreu D, Gadgeel S, et al. Pembrolizumab plus Chemotherapy in Metastatic Non-Small-Cell Lung Cancer. $N$ Engl $J$ Med. 2018;378(22):2078-2092. doi:10.1056/NEJMoa1801005

44. Shimoji M, Shimizu S, Sato K, et al. Clinical and pathologic features of lung cancer expressing programmed cell death ligand 1 (PD-L1). Lung Cancer. 2016;98:69-75. doi:10.1016/j.lungcan.2016.04.021

45. Takada K, Toyokawa G, Okamoto $\mathrm{T}$, et al. A Comprehensive Analysis of Programmed Cell Death Ligand-1 Expression With the Clone SP142 Antibody in Non-Small-Cell Lung Cancer Patients. Clin Lung Cancer. 2017;18(5):572-582. doi:10.1016/j. cllc.2017.02.004

46. Cha YJ, Kim HR, Lee CY, Cho BC, Shim HS. Clinicopathological and prognostic significance of programmed cell death ligand-1 expression in lung adenocarcinoma and its relationship with p53 status. Lung Cancer. 2016;97:73-80. doi:10.1016/j. lungcan.2016.05.001

47. Du W, Zhu J, Chen Y, et al. Variant SNPs at the microRNA complementary site in the B7-H1 3'-untranslated region increase the risk of non-small cell lung cancer. Mol Med Rep. 2017;16(3):2682-2690. doi: $10.3892 / \mathrm{mmr} .2017 .6902$

48. Nomizo T, Ozasa H, Tsuji T, et al. Clinical Impact of Single Nucleotide Polymorphism in PD-L1 on Response to Nivolumab for Advanced Non-Small-Cell Lung Cancer Patients. Sci Rep. 2017;7 (1):45124. doi:10.1038/srep45124

49. Zhao M, Zhang J, Chen S, Wang Y, Tian Q. $<\mathrm{p}>$ Influence of Programmed Death Ligand-1-Gene Polymorphism rs822336 on the Prognosis and Safety of Postoperative Patients with NSCLC Who Received Platinum-Based Adjuvant Chemotherapy. Cancer Manag Res. 2020;12:6755-6766. doi:10.2147/CMAR.S255072

50. Lee SY, Jung DK, Choi JE, et al. PD-L1 polymorphism can predict clinical outcomes of non-small cell lung cancer patients treated with first-line paclitaxel-cisplatin chemotherapy. Sci Rep. 2016;6 (1):25952. doi:10.1038/srep25952

51. Tao L-H, Zhou X-R, Li F-C, et al. A polymorphism in the promoter region of PD-L1 serves as a binding-site for SP1 and is associated with PD-L1 overexpression and increased occurrence of gastric cancer. Cancer Immunol Immunother. 2017;66(3):309-318. doi:10.1007/s00262-016-1936-0

52. Krawczyk P, Grenda A, Wojas-Krawczyk K, et al. PD-L1 gene copy number and promoter polymorphisms regulate PD-L1 expression in tumor cells of non-small cell lung cancer patients. Cancer Genetics. 2019;237:10-18. doi:10.1016/j.cancergen.2019.06.001

53. Yu Z, Li Z, Jolicoeur N, et al. Aberrant allele frequencies of the SNPs located in microRNA target sites are potentially associated with human cancers. Nucleic Acids Res. 2007;35(13):4535-4541. doi:10.1093/nar/gkm480 


\section{Publish your work in this journal}

Pharmacogenomics and Personalized Medicine is an international, peer-reviewed, open access journal characterizing the influence of genotype on pharmacology leading to the development of personalized treatment programs and individualized drug selection for improved safety, efficacy and sustainability. This journal is indexed on the American Chemical Society's Chemical Abstracts Service (CAS). The manuscript management system is completely online and includes a very quick and fair peer-review system, which is all easy to use. Visit http://www.dovepress.com/testimonials.php to read real quotes from published authors. 